\title{
Seeking Experience in Architecture: Corporeal Attempts at Perception and Conception
}

\author{
Katharina Voigt and Virginie Roy
}

\begin{abstract}
This contribution presents the proceedings from a series of transversal university projects, addressing bodily forms of knowledge concerning the perception, inquiry, and conception of architecture. It retraces the phases of different manners of investigation over a threesemester teaching cycle, addressing perceptions and experiences of architectural spaces. The proceedings of, and results from the seminar cycle are documented and framed with an introduction to the applied methods and ways of working as well as their reflection and evaluation. These varying approaches all center around the questions of how to bring body-based and incorporated knowledge concerning architectural space to awareness and how attention to sensual and corporeal ways of perception can be increased. Thus, it investigates how the spectrum of design methods in architecture can be extended in order to actively include bodily forms of knowledge in the anticipation of spatial experience in the design process. The article introduces a concept of "Architecture Imagery« as a way to include bodily ways of knowing and body-based practices in the perception and memory of lived experience and the process of architectural design.
\end{abstract}

Keywords: Corporeal Experience; Architecture Imagery; Body-Knowledge; Sensory Perception; Embodied Phenomenology; Transdisciplinary Practice-Related Approach.

\section{Prologue}

Essential to this investigation is the question of how an elaborate consciousness for multisensory, sensorimotor, and sensual architecture perception can provide more refined access to the incorporated knowledge gained through experience, in order to actively implement it in the process of architectural design. Such analysis is pertinent, as it allows for the anticipation of future experience already present in the associative, and inventive processes of imagination and creation - reaching beyond the visual senses of the imaginary. 
In the following text, the thematic field of bodily knowledge, corporeal and sensual experience, and body-based perception of architecture is unfolded using various means: It opens with an introduction to the project's phases, centered around the discourse and investigation of sensual, perceptual, and corporeal dimensions of experiencing architecture. Moreover, the investigation presents an assembly of reports on encounters with a broad variety of different buildings and the corresponding evoked sensations. These seek to replicate the sensual and poetic qualities of the encounter through writing, visual documentation in photographs and sketches, as well as through corporeal forms of conveyance. Physical gesture is explored as a tool to retrace incorporated knowledge and to express lived experiences and impressions in bodily ways. Finally, the process and proceedings of the working cycle are reflected with specific focus on their potential to form a basis of knowledge as well as an extension of the methodological approaches to architectural design.

\section{Exploring Experience}

The seeking of experience in architecture is based on raising awareness of diverse modes of perception. At the center of this exploration lie sensory and bodily approaches to investigate the efficacy of architecture. The principle research question guiding transversal exchange over a three-semester-long university project examined how lived experience, sensuality, and movement in architecture can be accessed, collected, and articulated. Starting from this acquired knowledge base with respect to experience, we are concerned with the question of how we as designers - in architecture, but also in other disciplines - can draw from conscious experience and the knowledge gained from it: our own experience forms the impulse and basis for our own creative process and design. This interest created the framework for open-ended research in collaboration with master students in the Technical University of Munich's Department of Architecture under the supervision of the authors. The experience of architectural space was investigated in a transdisciplinary practice-related approach.

Architecture and movement have a complementary effect on each other: The spatiality of a building is only revealed to the recipient by moving through it, while the architectural form has a decisive influence on the type and expression of movement carried out within it (Janson/Tigges 2014: 118-120). Our bodily constitution and the bodily knowledge gathered from 
previous spatial experiences of architectural space suggests that architecture has a direct effect on us - one that we literally feel in our own bodies. The human and the architectural body encounter each other as related and yet distinct bodily forms and resonate with each other regarding their respective impact, expression, and gestures. Accordingly, both can be defined as spacious, spatial, and material. They are reciprocally interdependent, as the spatial sphere of the human body is affected by the architectural form itself and responds to it in gesture and movement. The spatiality of architecture is only revealed in movement. By walking through it, the spatial sequence is comprehended and thus inscribed by the body (Noë 2004; Janson/Tigges 2014: 118-120; 144-146).

The sensory perception of architecture is complex. It is a synesthetic experience. Upon entering an architectural construct, one is absorbed into the immersive experience of the surrounding setting. When diving into the exploration of a building, a sequence of rooms or urban spaces, moving within the spatial layout and being moved by its impetus and sensual impact, reciprocally condition each another. As we move in space, we are moved by the space; it attracts our attention, invites specific movements, and influences the types of movements conducted within it. Movement gives access to experience. Deeper layers of understanding and experience emerge in the contingency of moving in space. Investigating movement and the sensation of being moved promotes the inclusion of this bodily knowledge in research. The body here is regarded as an all-encompassing sensory entirety, which grants access to sensual perception and mediates perceptual sensations. Aspects like being surrounded, being included, and being enclosed in an immersive spatiotemporal situation are addressed in the investigation of architecture experience. In relation to the physical presence of a building, an individual interacts with it corporeally, through resonance and dialogue between the body and the architectural space. Architectural space, here, is understood as enclosed and containing space, as a context within which an individual immerses themselves and moves, and which, respectively, only unfolds its entire complexity upon its exploration in movement. It can be a sequence of rooms, a series of inner spaces, but also an affiliation of spaces in cities - such as alleys, streets, and squares. All spatial typologies - be they transitory spaces, places of rest, interstices or thresholds - evoke an allencompassing holistic and immersive feeling. The entirety of an experience cannot easily be dissected into its individual facets of experience; rather, it is an overall impression that we gain by experiencing a situation. Sight and 
hearing, sensory experiences to which we have heightened tangible access and which are often perceived to be predominant, overshadow the complex correlation of all senses, whose influence we experience as implicit knowledge beyond conscious access.

Thus, the project of experiencing architectural space in a body-based context examines the spatiality of the body and its movements. The individual lived experience of the participants forms the essential basis upon which the knowledge of perception builds, while reflective and superordinate texts from various disciplines - such as architecture and art studies, phenomenological philosophy, theories of perception, psychology and cognitive sciences - broaden the spectrum of perspectives discussed. Initiated by the question of how architecture affects the experiencer, special focus was placed on observing individual perceptions and sharpening awareness of one's own sensations. Furthermore, it is not only important to perceive these observations, but to also make them accessible to oneself through different means of expression, and, in an additional step, to make them comprehensible and legible to others. In this sense, this inquiry concerns reconnecting to the sensuality of experience, as well as about seeking ways to communicate and transmit it.

\section{Acquainting Body-Knowledge}

In the first step, each participant was asked to visit a chosen architectural site and pay particular attention to their initial perception as well as how their process of exploration revealed the site to them. The exploration was to be non-evaluative, guided by the senses, and allow for the emergence of whatever came up, without any pre-conceived focus set beforehand. In order to increase the ways in which the building can be perceived, the sensations and observations gained upon its exploration were refined in descriptive essays which portrayed the individual, subjective, and situational lived experience of the place and which were supplemented with photographs that reflected the individual's personal perspective. The individual experience of architecture is examined with particular regard to the method of approaching the building, to thresholds and transitions of the architectural tissue, as well as to the spatial structure. In dialogue with the body, the focus centers on the impulses of movement and the sensual impact evoked by the structure.

In the following semester, the initial task remained the same as in the first. However, in order to uncover the substance of the observations, the 
participants did not only draw from within themselves but were interviewed by another participant, who asked questions to refine their descriptions. Meanwhile a third person was asked to witness the gestures and movements which emerge, while trying to find the right words to express lived sensual and tacit qualities. In the search for words before verbalization, somatic and body-based practices enabled expression through gestures and movement. ${ }^{1}$ Therefore, in the subsequent work process, particular attention and vigilance were paid to the body and the involvement of gesture and movement. Just as it is difficult to differentiate between different aspects of experience, it is difficult to put sensory and multisensory experience precisely into words and expression. Beyond verbalization, corporeal forms of expression allow for instant responses to the lived experience.

Movement and gesture allow one to reconsider, retrace, narrate, or mediate the immediate impression perceived and to express it by corporeal means. Therewith, the verbal translation of the experienced sensation becomes obsolete. What affects the body is articulated through the body. The body remains the medium of expression that brings forth an immediate description of the experience. Working manners from contemporary dance, and particularly improvisation, choreographic methods, and somatic practices, were introduced as methods to exploit and apply bodily forms of knowledge and to bring the body as medium a of perception, conveyance, and expression into the discourse.

\section{Collecting Sensual Experience}

As the research cycle progressed, the focus increasingly shifted from the dominance of visual observations to attuned awareness of multi-sensory, complex, and experiences, emphasizing the sensual, sensorimotor, corporeal, and body-based dimensions of lived experience. In the last phase of the cycle, this shift was encouraged by omitting the visual sense through blindfolded, tactile exploration of a building: In teams of two, the participants explored the space of the building. The blindfolded person explored

\footnotetext{
1 In the chapter»Poetics of Movement«Laurence Louppe states: »lt could be also be said that smovement concerns the whole body, and that gesture is more fragmentary, visibly at least, making movement more global, closer to posture and thus to an unconscious charge which is more interesting poetically than a segmentary gesture which is >decided and clearly semitted« (Louppe 2010: 72).
} 
the building and was free to find their way through tactile exploration, while the second person observed and accompanied the exploration to create a safe space and to witness the process. In this activity, the blindfolded person actively guided the exploration of the space, with the protection given by the second participant creating the freedom to fully discover. Starting with slow movements of palpating and touching the surfaces of the architecture, after a while the blindfolded explorers gained more and more freedom to let go of the support of touch, and began to move around and to sense different aspects of the bodily discovery of space. Also during this activity, the lived experience was recapped and unraveled in dialogue between the partnering participants in order to deepen the consciousness of the lived experience.

However, in contrast to the previous phase, movement and gesture did not only unintentionally occur during the conversation, but the whole body was brought to the fore and actively involved in movement. While the two prior phases explored how sensual experience affects and involves the body, the moving body became the center of attention in this final phase: It was analyzed as a medium to explore, a channel to provide access to sensuality, movement, and gesture, and as a tool for the discovery and examination of place. As movement and gesture had been essential for the exploration itself, they were investigated as integral parts of the exploratory experience. Along with the recall and reflection of these sensations that emerged during the interviews came the refinement of gestural expressions, which were then elaborated upon as an embodied essence of these key moments of experience.

The impressions gathered in this process assemble a variety of sensations, which can be retraced in gestures and movements. Recalling these sensations, an individual's memory of the experience sets the participants in motion. They either embody the sensation or reenact the actual movement of exploration or its associated imagery. In the empty space of the central counter hall of the main customs office in Munich, where the investigation took place, this collection of sensations was recalled and retraced in an act of improvisation, - as a performative intervention through the body in the space -, to allow the key moments of the experience to spontaneously emerge in movement and gesture. The choice of place was also essential to the experience, as the qualities of the building impacted the movement. The actual impressions are retraced in the lived moving experience. 


\section{Assemblage of Observations}

The following collection of works - descriptive observations and gestures presents proceedings from the process of investigation. It includes excerpts from essays and photographs of gestures to document the various facets of individual architectural experience. The diversity of forms and styles of representation is explored, as the works are arranged in a complementary manner, without attempting to align them with one another. Corporeal and somatic observations are put into words and narrated in detailed descriptions, emphasizing the sensations assembled throughout the exploration of a building or a sequence of rooms. They are traced in tangible discovery and recaptured in gestures and movements.

Gathered from several selected places, the following narrations convene the individual observations and lived experiences that occurred during the encounters with such buildings. Upon these subjective, situational, and often distinctly sensual and body-relating contemplations, emerging thoughts and attentive observations are brought together as fragments, bits and pieces taken from the complex, synesthetic overall experience.

The following contributions are excerpts from seminar works by master's students from the following courses:

\section{- "Architectural Perception"}

Seminar held by Katharina Voigt in Winter 2018/19 at the Technical University of Munich, Chair for Architectural Design and Conception.

\section{- "Phenomenology of Architecture»}

Seminar held by Katharina Voigt in Summer 2019 at the Technical University of Munich, Chair for Architectural Design and Conception.

\section{- "Architecture Experience»}

Seminar held by Katharina Voigt and Virginie Roy in Winter 2019/20 at the Technical University of Munich, Lecture Position, Questions from Science and Society in Architecture and Urban Planning. 
122 Katharina Voigt and Virginie Roy
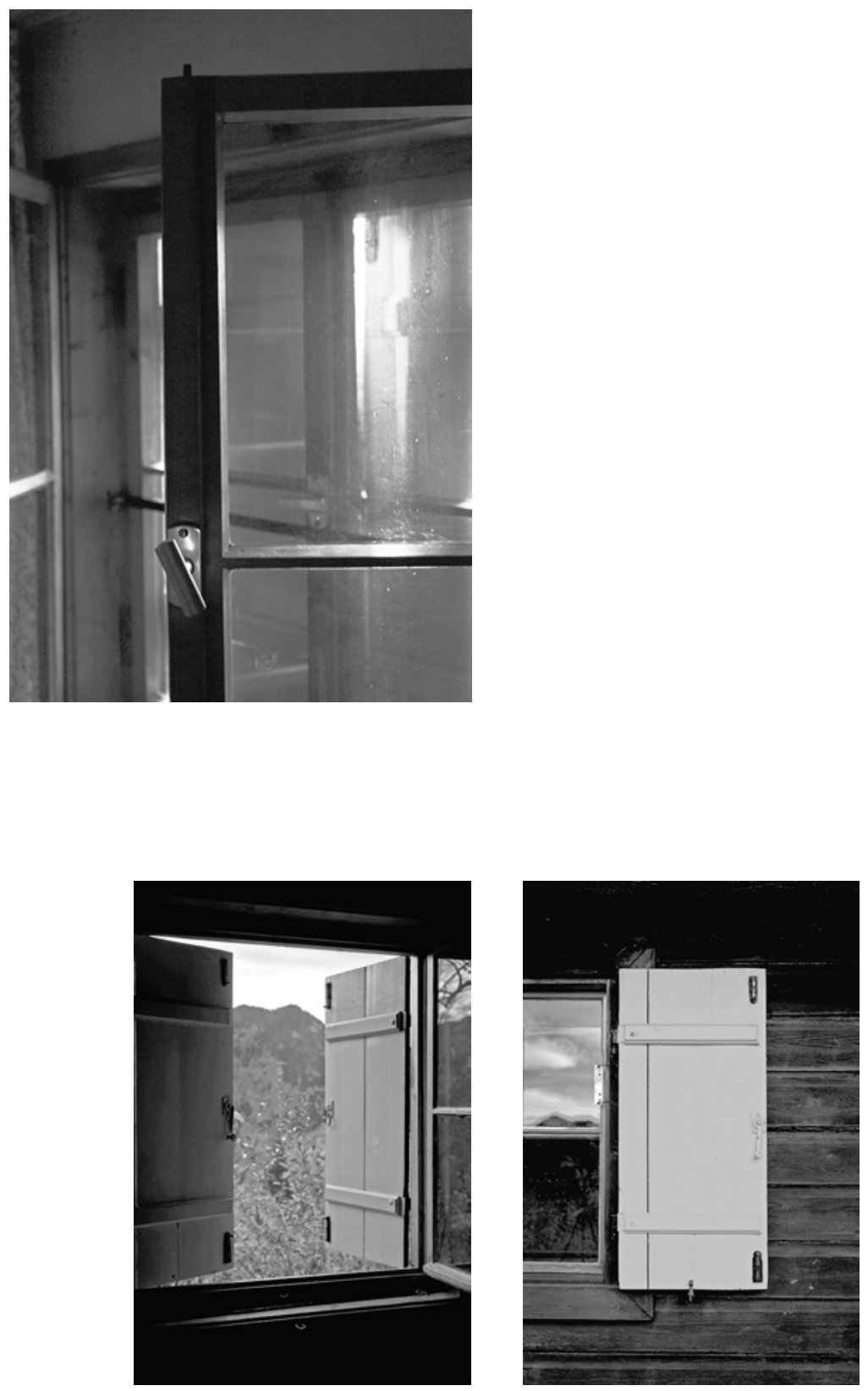


\section{Quirin Goßlau: Cabin, Tegernsee}

»From a great distance, the visitor is able to view the hut's surroundings, such as the forest in the background; at a closer distance, however, the dark wooden material surrounding the structure becomes the main focus. Only increasing proximity and finally entering the hut enable the visitor to become aware of the more subtle details. Yet closer examination and conscious perception in turn, require selecting and focusing one's field of vision.«

»The first glimpse into the main room shows a dark expanse countered by faint rays of sunlight, which create small crevices in the closed shutters on the opposite side of the room, appearing to cast strikes of light in the haze. Opening them requires loosening numerous wing screws on each window by hand and thus moving through the inside of the building, as well as moving around the outside of the cabin, to individually remove the counterparts of each screw.«

»The successive action of opening all seven windows and the recurring entry and exit between the inside and outside make active movement an obligatory ritual upon arrival, even for a recurring visitor. Only with the opening of all shutters and the sequentially established connection between the inside and the outside of each opening is the visitor finally able to enter the cabin. Each view from the windows increasingly locates the structure between the contrasting sides of valley and slope, lake and mountain, as well as between two forest edges on the side of the gable.»

»The mental distance and perspective of the surrounding landscape are reinforced by the feeling of refuge that the hut provides, an escape from the hustle and bustle of the big city. The ascent to the cabin, which is small and inconspicuous in color, is barely visible from the lake and reinforces this perceived distance. Ultimately, the visitor looks back into the valley and across the lake as an uninvolved, neutral observer, thus keeping their surroundings at a safe distance.«

»Situated in the surroundings yet shielded, the shutters open like outstretched arms: In its appropriated state, the cabin represents an intelligible and assured relationship between inside and outside, and is thus an ideal environment for the visitor and their self-reflection.« 


\section{Matthias Peterseim: Domus Aurea, Rome}

»The first section near the entrance looks like a utilitarian corridor. From here on we follow a sequence of rooms arranged in a polygonal manner. It is difficult to orient oneself within them without visual references to the outside. We quickly pass through several of the brick-vaulted rooms or corridors. In other, better preserved halls, we pause. We detect places that, simply due to their character, prompt us to stop. The respective purpose or use of the rooms eludes our attention. Instead, we concentrate on exploring the very character of the place.«

»lt is astonishing that by using the same means, such different shapes and geometries have been created in the very same complex. The rigor that often comes from symmetrical layouts and axes is not noticeable here. While the individual room is symmetrical, the sequence of rooms is not. Thus, the structure of the underground Domus Aurea does not tell us much about its spatial arrangement. It is only revealed as we walk through it.«

»While passing through, the building resembles a pulsating, organic body. As it has no exterior, I have no choice but to enter inside it. The subterranean structure affects my body immediately upon entry by making me attune to a new atmosphere. While my eyes adjust to an enormous change in contrast and only slowly get used to the darkness, I become aware of other sensory impressions. The hot dryness of the outside gives way to the cool dampness of the interior. In this way, it is immediately clear that I have moved right into a different environment without hesitation. A glance behind alone would not be enough to verify this change; it is my body that really experiences the sudden adjustment. However, as quickly as the change comes, my body has the ability to adapt to new circumstances just as quickly.«

»My eyes move rapidly back and forth from the earthy floor below my feet to the vault above my head, to the side toward the prohibited spaces. Using my visual sense, I explore the spatial structure. In some directions, the further extensions of the space - which include not only the corporeal, but also the visually grasped-run into the void. In a floor plan, there would be open ends here, without specific frontiers. In the depth of the aisles the spaces fade into a blur. They resemble black holes: They are immaterial and inevitably attract glances, generate curiosity, and almost physically repel and resist the visitor.« 
»In this place, we as knowers encounter much more than the solely visible; in this way, we additionally enter into dialogue with different layers of history. We recognize the construction method and connect it to the Roman Empire. We know that the walls were once covered with marble and stucco. Today, we see a porous brick surface. We begin to wonder if we might like this brick texture - which seems almost monolithic - better than the original plaster and fresco decoration. But who can tell?«

»Every place we visit is trivial in its own way; we can always rationally break it down into its distinct components and describe them. Humans possess this characteristic as well, in particular those that exist within the context of Enlightenment >modernitys. We strive to get to the bottom of things and to explain them, yet we lose the imaginative access to space and things." 


\section{Viktoria Kelderer: Warrior Memorial, Munich}

»Despite the lack of a door, the first step inside is a very special experience. Before I take my first step, I always ask myself which of the twelve staircases is the right one to take this time. It becomes a kind of game to choose a different way into the space each time and, in turn, to take another one on the way out.«

»The inscription >To Our Fallen< triggers certain uneasiness; associations with death or tombs come to mind. The steps become slower, more hesitant. My head is submerged under the ceiling tile at the next step and suddenly the obscurity vanishes. The light of the sun no longer blinds my eyes. They adjust rapidly to the new environment and I pause for a moment to appreciate what is revealed to me.«

»After a long time of looking at the architectural sculpture from the outside - from a distance, so to speak - the scale of the space finally becomes clear upon entering it. It encompasses an unexpected space, the stairs turn into normal steps, and the openings appear as entrances of a familiar size. In the center, however, lies another sculpture: the representation of a fallen soldier, carved from gleaming stone. Here again, my sense of scale becomes confused. This soldier of stone resting in the center of the room appears to be disproportionately large and makes his surroundings seem much smaller than they actually are.«

»The architecture is structured by the massive stone ashlars. Deep, massive barriers to the outside world alternate with similarly wide openings. The rhythmic character of movement makes me speed up. Where is the right place to pause?

»As I pass along, I run my hand over the surface of the stones. Contrary to my expectation, they are less cold than I thought. It seems that their warm color is more than just the chromaticity. My fingers glide from the precise edge over the broad surface to the other edge and finally fall into the void until the game begins anew.«

»The surfaces turn out to be smoother than I had suspected, the strong grain is only striking in terms of color; it cannot actually be tangibly detected. 
The striking pattern of the grain reminds me of old trees. Thick deforested trunks that reveal a glimpse of their age in the form of countless annual rings. Thoughts begin to wander: Rings for years, rings for days, and rings for human lives. And again I shiver.«

»The oppressive effect of the large block of stone towering above me makes me abruptly aware of my own physicality. The cover plate presses heavily on one's shoulders. The grain of the stones, reminiscent of annual rings, immediately guides one's own thoughts in new directions: sphysically, as anatomy and skin, as mass, membrane, as fabric or sheath, cloth, velvet, silk and shiny steek (Zumthor 2006: 31). The monument exerts its effect on the visitor through its skillful interplay of material and form.«

»If I did not know that this is a monument to fallen soldiers, I would assess the gravity of the place in a different way. Is this kind of perception now less true than a perception that occurs solely through the body and the senses? It would not have been possible to grasp the significance of the place only through the senses. Of course, the architecture in itself has the gravity necessary to express that it is a special, contemplative place, but wouldn't the monument be meaningless if perception stopped here? The explanatory component of the pictorial symbols on the stone blocks and the soldier inside are necessary elements of this architectural structure.«

»I continue to climb the stairs, but the redeeming arrival outside does not yet occur. I am still much deeper in the ground than the park's other visitors. I continue to work my way up. From the gravel court, up the stairs, past the hedges, to the very top, where the trees and individuals visiting the Hofgarten finally appear and immediately absorb me, creating a distance from what I have just experienced. Once again, the anonymity of the city engulfs me.»

»I turn around one last time. It is only now - looking back and against the background of what I have just experienced - that the abstract structure of stone blocks reveals itself to me as a symbol: broad-shouldered soldiers standing side by side, holding a protective shield over a fallen comrade.« 
128 Katharina Voigt and Virginie Roy

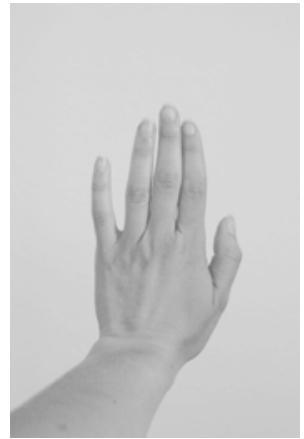

"confrontation"

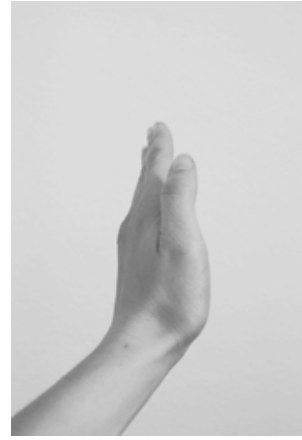

»linearity»

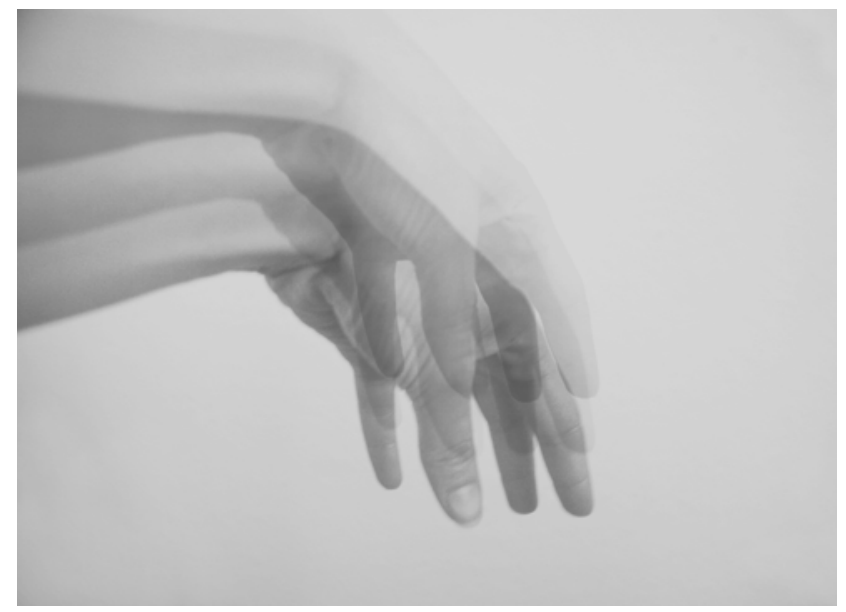

"placement« 


\section{Melanie Sommerfeld: Museum La Congiunta, Giornico, Ticino}

»Through the growing feeling of proximity that engulfs me, I begin to feel a connection with the architecture, the proportions of which I perceive as coherent in relation to my body. At the same time, I recognize details in the materiality, such as the horizontal division of the surfaces through a formwork pattern in the concrete, which emphasize the linear movement.«

»l hear the space's sounds in a muffled manner - the chirping of birds, the murmur of the river, and the church bells - create another reference to the outside world. Thus, the structure provides protection and conveys a feeling of being enclosed without excluding the external environment. Reverberation is characteristic of the sound in the rooms and I become aware that I whisper when talking to other visitors."

»The movement in the interior, which is initially linear and finally bends in the direction of the adjoining space, finds its counterpart in the exterior space, in which I walk linearly along the museum until I alter direction toward the entrance door. These two figures of movement intertwine and must be retraced back in the same way when leaving the place.«

»As I contemplate the landscape, I become aware of my own size, and in comparison to the expanse of the landscape, I perceive my own spatial sphere to be pushed back to the contours of my body. The dimension of the spatial sphere depends on the sensory perception and occasionally corresponds with the boundaries of space. Thus, I perceive the expansion of my spatial sphere during the widening of the walkways around the building in one way, but sense its minimal expansion in the face of the landscape space in another. At the same time, my perception extends beyond the limits of my body, and I can clearly perceive the building at my back, even though it is not in my field of vision. I feel the protection of the canopy and simultaneously, in contrast, the exposure to wind and weather.»

»While architecture leaves an impression on me, generates memories, and shapes my experiences, I express myself through my movements in spaces." 


\section{Lisa Schröter: Public Pool Müller'sches Volksbad, Munich}

»I climb a stone staircase and perceive distinct sounds. I hear echoing voices and the water. I see the lockers. In the background, a spectacular view emerges: I see the bright blue of the water and hear noise from a throng of people. I get closer to the parapet. I can overlook the entire hall. A moment of astonishment! I look down and, for a while, observe how people behave, where they put their towels. I continue walking to my locker. I open the wooden door and put down my things. What do I need, what do I take with me, what is important? From up here I feel safe, unobserved. Here, I am in the position of an observer. The thought of going down and becoming someone to be observed makes me feel insecure.«

»After I get out of the shower, I want to descend the big stone stairs into the pool. I step down into the water. The water is cold. I dive in and stand for quite a while watching the others use the free lanes. I think about how best to blend in. I move from a vertical body position to a horizontal one and begin to swim. It is a different pace at which I now glide through space, a different sensation. I feel the water flowing between my fingers and the effort of resistance. Meter by meter I work my way onward. I look around the room, marvel at the vault. I watch the sun graze the plaster and illuminate the upper dressing rooms. Over and over I travel the same distance. My line of sight alternates back and forth.«

»After several laps, I pause. I hold on to the edge of the pool and look around. I notice that I have once again become an observer. In contrast, while swimming, the faster I became, the more I strained, the more my attention was focused on myself. I swim one last lane and climb the cold stone steps again and leave the water. I now perceive my body in a completely different way. My legs have become tired and heavy.«

»Now I enter a smaller hall. It is much more intimate than the first. I no longer feel exposed. I slowly and carefully enter the water by walking down the large stone steps that lead into the pool. The water is very warm. Only now do I realize how cold I was when I was walking alongside the pool. The water in this small pool feels very pleasant. In this basin I can linger, there is no need to draw lanes. There is no compulsion to swim in an orderly and speedy manner. I am disturbed by the echoing noises, by the numerous voices.« 
»For the first time, I submerge into the water. Silence. Murmurs. Listening to my own heartbeat. I let myself drift, swim slowly at my own pace. I take a good look around the room. Here, I feel safety and security in the room. Through the window I see that it is windy outside and slowly getting dark. I am in a fortress, in a protected space. There are only a few glimpses of the outside world. Only the here and now exists in this space, everything else is shielded and unimportant. I feel secure in the space, firmly located despite my floating state in the water. I perceive the volume of space in a completely different way because I am carried and surrounded by water, my feet not touching the ground. I can perceive and sense the volume of space beneath my body through my movements. The darker it gets outside, the quieter it becomes in this space, making me feel more safe and secure.«

»While my movements in the elongated pool's water are directed and brisk, I can let myself drift in the smaller pool. The space is smaller and seems more intimate. My gaze is caught again and again in the oval dome, visually retracing its curved shape, while floating in the water in a circular motion. In this pool my movement is undirected. I constantly vary my directions of movement, diving my head underwater. Sometimes I let the water move me and I lie almost motionless on its surface. My body is relaxed. In the big hall, on the other hand, I constantly keep my muscles tense, always in motion.«

»The moment of entering the water is a tactile experience. The texture and temperature of the stone can be felt with bare feet. The coldness of the water initially presents a barrier, but it is hesitantly overcome. The surface of the water can be clearly felt, like a line enveloping the body.«

»When leaving the water, the breeze becomes noticeable on the skin. The moment of touching the cold, rough stone of the stairs contrasts sharply with the warm water in the smaller bathing hall. It now becomes a memorable impression to stand firmly on the ground in the room again. The awareness of the body changes significantly. One's own corporeality is brought to attention.« 

seminar work, 2019. 
134 Katharina Voigt and Virginie Roy

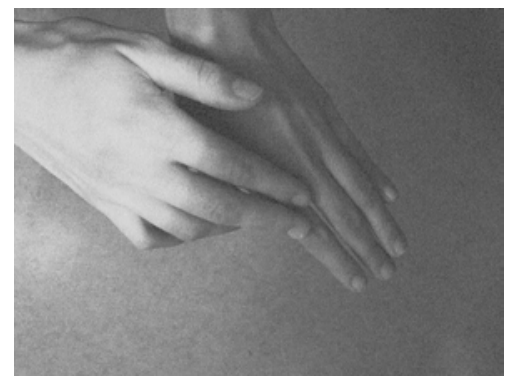

»sensing"

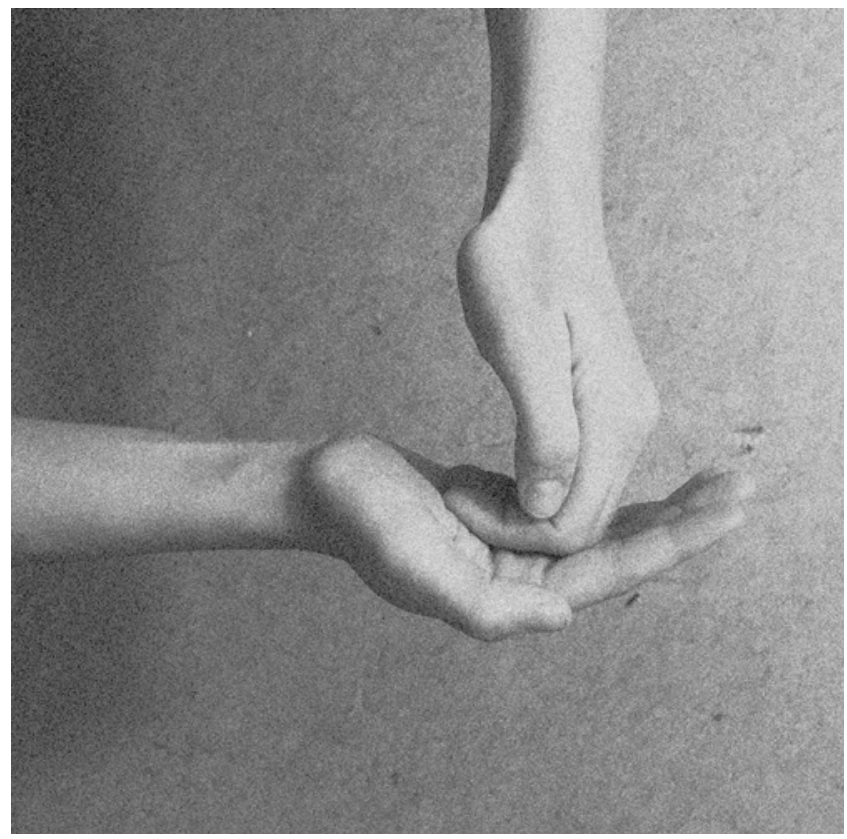

»immersing« 


\section{Laura Betz: A Sense of Indulgence and Belonging}

»My initial timidity gives way to an urge to discover. My fingers explore my immediate surroundings. I shimmy along railings and balustrades, always striving to be in close contact with the elements that surround me. Free in space, I have no chance of orienting myself in the building."

»The noise of the city penetrates dully through the walls of the building. While shortly before I had delicately wiped the dust from the radiators with attached stone cornices as I passed along, the temperature has changed now and it has become a little chillier. My premonition is confirmed when I arrive at the end of the stairs. The soles of my feet plunge into a soft material. I feel my body slightly sinking into a material, which, to a certain degree gives way under my load. It feels as though I am walking in a surface itself. I am carving my way through the space instead of treading on a hard surface and pushing off as I did before. But can I be sure that I am on a doormat? If so, the entrance door should appear right away. I continue shuffling my feet across the mat until I reach the rubber edge where I stop abruptly, arms outstretched. Where is the door? There should be three doormats in a row and I should experience a halting, pausing reaction to the supposed end of each mat. I feel amazement and annoyance. At the same time, I feel my partner's warm, reassuring palm on my right shoulder. With the opening of a heavy wooden door, the tension is released. I step out into a rush of fresh air. «

»The theme here is transition, movement, stepping through and out of something familiar into a vague spatial memory. Whereas before I only saw a sequence of large, clearly proportioned rooms, I now perceive a branched system of spaces, the beginning of a labyrinth or perhaps a system of tunnels or channels.«

»Finally, apart from the individual experience of a situation, I would like to record the scenario of the entire, collectively experienced spectacle. Unexposed to the gaze of others, a collection of individuals roam an unfamiliar building in search of the unknown. What we share in the end is emotional information, the breakthrough to hidden spheres of perception. This information cannot be described as an increase in knowledge of building data, but arises from a unique event in a unique constellation. We have become accomplices, witnessing a common experience.« 


\section{Melanie Sommerfeld: Envisioning the Invisible}

»My concentration is intensified and shifts to my own body, which gains presence and comes strongly to my attention. At the same time, the relationship between my body and my environment becomes tangible, my body developing a more sensitive awareness of the space - seeming to reach out into it. I perceive the space, which, to me, is without dimension when I stand still, as something enclosing and surrounding me. This space turns into a space of action that I explore for sensory stimuli of various kinds, evoking a constant focused vigilance that is present in me.«

»In movement, sensory perceptions multiply and acquire a spatial dimension. Through the contact of my feet with the ground, which seems to me a strong point of reference since it is the only point of contact between my body and my environment, I feel the resistance and can differentiate between a yielding and a rigid ground. In addition, the movement produces sounds that evoke associations and memories of previous experiences, and I imagine a wooden or a stone floor. The visual stimuli I absorbed immediately before the blindfolded architectural experience also influence my perception. For me, a particularly memorable moment of perceiving the floor is when I step over a threshold that stands out in comparison to the flat floor and forms a clearly perceptible linear elevation, which can be experienced by pressing it firmly against the lower side of my foot.«

»My hands, in addition to scanning the surfaces for which I am in constant search, also serve as a point of reference to grasp the dimensionality of the space. I stretch my arms out in all directions, until I meet the resistance of the material withstand of a surface or on the contraty, I have a sensation of being lost in the perceived infinity of space. Here, my body to me resembles the center of the surrounding space. Through this expansion of my body, I feel the relaxation of my body, which enables me to move freely in space.«

»During my experience, the haptic stimuli not only represent the only direct contact with my environment-already initiating the awareness of the point of contact between my feet and the floor, - but are also reflected in my change of behavior as I try to understand the architecture through haptic sensations. My altered approach to space thus manifests itself in touching the materials, listening to the space, and actively perceiving scents.« 
»For certain situations, our memory is oriented more towards bodily experience, simply because a specific movement - those associated with ascending a staircase, grasping a handrail, or opening a heavy door - have been imprinted in memory incisively as a figure of movement (Janson/Tigges 2014: 198). I experience this in particular at the moment of climbing the stairs, where, without seeing the steps, I can retrieve the necessary movement from my body memory and conduct it. Through the movement of the body, which is strained when climbing the stairs, a space of tension is thus created which stands in contrast to the free and loose movement in the large hall. Here, the body also provides me with orientation and allows me to envision the dimension by letting my foot travel along the stairs in order to grasp, with the help of my imagination, where I am on the stairs - when they begin, when I am on the last step, and what the measures of the steps are.«

»When recalling the memory from the architectural experience while experiencing other spaces, the experiences become interconnected, so that spaces no longer form separate entities, but are interdependent. Ultimately stemming from the interweaving of all previously experienced places and spaces, my imaginary space and view of the world emerges." 


\section{Pauline Wessel: Experiencing the Imagery}

»A hand, resting on my shoulder, directs me through the room and protects me from obstacles of any kind. At the beginning of the exploration with closed eyes, I see myself moving in the imagined coordinate system and my position in relation to the individual components and the objects in the room. However, the more I engage in perceiving the space without a visual background, the more I lose my orientation and sense of security. Slowly, groping with my feet, I move through the room, taking one uncertain step after the next. We climb several smooth steps to a landing and move to the wall enclosing the room, which I explore with my fingers. I grasp cool panes and realize that they are windows. Again, we descend a few steps, back onto the smooth stone floor of the hall. Although I know that I am now back on level ground and that no more steps are to be expected, I tentatively move my foot forward, expecting to find another step. The feeling of potentially fallingdowntheimaginedstairswith thenextstep prevailsovermeforacertain period of time that I cannot define more precisely. I continue to move through the room, putting one foot in front of the other with a dragging motion, while the sensation of the possibility of falling down a staircase slowly fades.«

»Paying attention to my slow progress with dragging steps, feet barely lifting off the ground, it becomes clear how the smooth, stone floor is perceived and how the body reacts to it. The architectural body -its spacial void as well as its material outline - and the sensing human body are in direct exchange with each other and create a space of movement for me, in which I walk and seek my way. As a gestural element, the steps of the stairs, among others, should be mentioned. As a movement-leading material shapes, they provoke differentiated behaviors: While climbind the stairs, the foot bumps against the first step and recognizes it as such. Carefully, the foot is lifted and placed on the elevated level, tracing the second, again inching forward to recognize the following step. This process is repeated until the landing is recognized by the lack of resistance to the foot. The staircase as a spatial gesture produces uncertainty in the steps and the exploring movements of the feet. Through this movement, it becomes clear that the bodily sensing is decisively addressed by architectural means.« 
»Without vision, the space is grasped, palpated with the hands, feet, and arms, thus attempting to recognize objects and architectural elements. On one hand, the suggestion of movement is directly perceived, since bodily communication involves the interplay of the request for movement emanating from the given object and the associated action. The perception of objects implies an act of incorporation (cf. Schmitz 2005: 100). As the hand feels the surface, its material and thermal nature, understands it as a wall, recognizes stairs with the tips of the toes and the sole of the shoe, takes one step after the other on the smooth and even surface of the previously climbed platform, it becomes clear once again that the ssuggestion of movement [...] belongs directly to the object [...], without it, it cannot be realized (Schmitz 1999: 45, author's translation). A concrete movement must be executed in order to constitute or confirm the idea of the sensed object.«

»Here, it is evident that the perception of architecture is always based on a process of memory, since individually perceived spatial sequences must be put together in a temporal sequence to form a whole in order to obtain a complete image of the built space. The individual spatial sequences must first be recognized, as already described, through palpation and incorporation, in order to connect the supposedly recognized spatial situation to the previous one in an act of memory. The subject tries to find orientation in space by matching the perceived spatial situation with the stored coordinates of the building in memory. The architectural space serves here on the one hand as an object and at the same time as a generator of memory at the respective point in time (Havik 2006: 190).«

»Like gestural space, poetic space suggests certain attitudes can deviate from the reality of things, as this example also shows. The bodily relationship to architectural space is manipulated (cf. Jäkel 2013: 50) in that the suggestion of movement actually emanating from the level ground - the steady progress - cannot be executed without the component of sensory memory determining existence. The suggestion of movement results here rather from the remembered architectural space, which at this point seems to be present as stairs. In the state of reverie, the associated sensory impressions determine the perception of the actual space, and the levels of memory interfere." 
140 Katharina Voigt and Virginie Roy

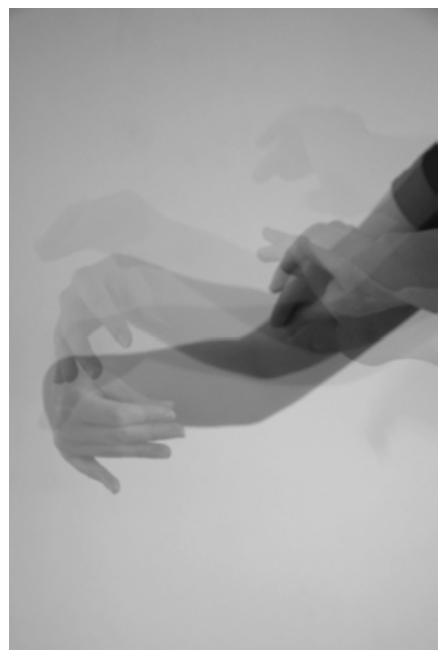

»adjusting«

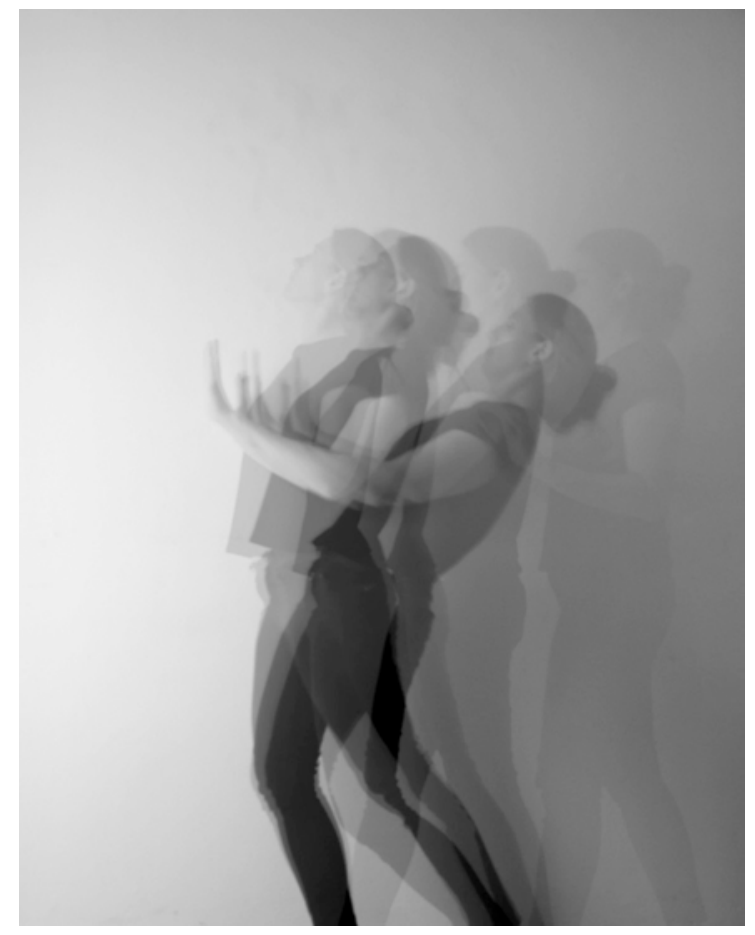

"against the wall« 


\section{Friederike Drewes: Expansion and Resistances}

»Against the Wall. The tips of my right toes feel the first resistance. This is followed by my two palms, which I hold protectively in front of my body throughout the experience. Springy and less hard than my toes, my palms meet a surface. This is where the movement of my whole body almost comes to a halt. The abruptness of this moment remains strongly in my memory.«

»Running. My steps become longer and faster. The cool air around me and the sounds of my footsteps make me suspect that I am in a large, oversized room. The quickening of my steps urges me to just go for it. For what? To make as far a distance as possible in a short time? I run and I don't feel the need to stop. There seems to be nothing around me and I have the impression of expanding. My steps are so large that the time of contact with the ground becomes smaller and smaller. I feel a rush and air on the skin of my face. I hear the brief tread of my shoes and the echoing in the space. There is room for me.«

"Adjusting. I experienced a different tension in my body during the last moment, which was impactful, as I have never felt the sensation of warmth or cold in the surrounding space so consciously. With every step I take, I feel a difference - gradually, and especially in relation to my initial situation, in which I generally felt comfortable. This sensation of comfort and ease is re-established again with every step - but therefore a brief phase of adjustment is needed. With each step I felt as if I was stepping over a boundary and into something new."

»I became aware that with all the above mentioned experiences I perceive a change in my body. But I wonder, how exactly do I feel this change? Something happens around me, to which I resonate and which I perceive in myself, in my body - inevitablly bringing all of my senses to awareness. As I envision this sequence of event, a liniar image emerges in my mind: It is an arc of tension, a diagrammatic representation, which breaks through a boundary at any moment of shifting focus and attention. In the beginning, there are distinct words for this sensation of the change of state, which I note in an associative manner: They are frontiers, bordering situations, moments of surprise, affect, and change, they are crossings or thresholds, entrances or exits.« 
142 Katharina Voigt and Virginie Roy 


\section{Epilogue: Toward an Architecture Imagery}

This reflection aims to investigate what underlies these exploratory studies and evaluates how they can reveal ways of knowing; furthermore, it analyzes how they can be versatile for the creative process in the architectural design. As already explored in the introduction to this contribution, the experience of architecture - both the spatial and space-related dimensions of experience are examined with particular care. The experience of space is addressed in regard to its corporeal effects and the spatiality of perceiving the body itself. While throughout the history of architecture the body has often been set in relation to architecture as its mold, its reference of scale, or its resemblance in proportion and structural arrangement (i.e. Le Corbusier's Modulor, or the personification of columns in Caryatides), here, the body is investigated in regard to its relation to space and the ways in which it engages in dialogue with its surroundings. In this sense, the body is understood as the starting point for sensory experience and as a medium and tool for exploratory movement in space. The body's corporeality is regarded in a phenomenological manner, aiming to develop an awareness of the experience and construction of knowledge that arises from it. As such, body-knowledge is brought to the fore and its objective is to unravel its capacities to interlink perception to conception.

With the intention of bringing the body into architectural discourse and addressing body-knowledge as an integral tool to provide tacit knowledge, the three following questions are essential:

- How can the body and movement - as media of experience and archive of memory - be opened up in such a way that the body's own reservoir of knowledge can be made accessible to the discipline of architecture?

- How can bodily-knowledge - gained with the (moving) body and anchored in it - be made available to nurture the architectural design and creative process of conception, as the core of the discipline and essential part of architectural education?

- Which methods can be introduced to access body-knowledge and to attune awareness to the sensual, corporeal, and somatic experience of architecture? 


\section{Discovering (with) the Moving Body}

Bringing body-knowledge into architectural discourse does not only demand reflection on how the moving body is involved in perceptual and creative processes, but also - in order to reveal a stable basis - seeks to address the discovery of the moving body as such and to foster the closely linked relation of perception and conception as an essential element of the design process. On this basis, it is then possible to invent a method that includes the body in both research and design in architecture.

Awakening the sense of creation through and with movement and bringing somatic practices and contemporary dance to the discourse on architecture experience provides possibilities to explore sensual creative architectural experience and the moving body in space. Therefore, preconscious, tacit, and implicit forms of knowing are brought to attention and the bodily ways of knowing, here, serve as tools to access them. All associative and imaginative processes draw from this embodied information. They (re-)create ideas and conceptions from prior experience and memory. It is the aim then to develop body-based ways of inviting designing architects to deepen their awareness of their body-knowledge.

In order to address the creative potential of the body - as a container of memory and experience, as a medium of expression, and as a sensory precondition to sensual perception - it needs to be asked, how the senses can be expanded to a broader sensitivity and how they can be relied upon, and furthermore, how the body - particularly the moving body - enables us to engage the senses more intensively. For this, the body needs to be acknowledged as an indispensable prerequisite for sensual and multisensory perception. As a medium, the body allows access to the experience and creation of space. These bodily gained and embodied sensations themselves are of crucial importance, as they form the incorporated basis of experience and memory, which creative imagination and thought draw upon and from which ideas and conceptions are preceded. Furthermore, this cultivates the notion of trusting the bodily forms of knowledge which are subconsciously already applied in intuitive procedures of the design process. As lived experience - in its manifold facets of sensual and multisensory complexity - reveals the origin of creative thought and imagination, its refinement improves the basis upon which creative processes are built.

Creating access to the experiencer's physicality results in active access to knowledge intrinsic to the body. Consciously getting into motion, perceiving 
with the body, and perceiving the body in motion offers a fertile extension of the existing methodologies in the discipline of architecture. The transfer of working methods from contemporary dance and somatic practice to architecture allows for the involvement of the body. It raises awareness of bodily and sensual perceptions and allows for the resolution of their complexity with distinct observation and analysis of its detailed aspects. In this respect, it is interesting to address it as a specific disposition in creation and to consider how it can be applied to the conception of architectural design to let ideas emerge through physical practice and consciously lived moments of bodily, sensual experience.

Based on the feedback of the participants in the three phases of the cycle, it became clear that the introduced working method would benefit their further studies - especially in the context of architectural design. The example of Free Master's Theses ${ }^{2}$ revealed how the students applied and adapted procedures of this working method to their own design practice and self-assigned tasks. For instance, designing a hospice for the dying, one student chose to exploit the extraordinary sensual and corporeal condition of the body in the terminal phase of life as inspiration for her design process. From the sensual particularities of the restrained body - the lying body, the vulnerable body, the body troubled by insecurity, fear, and unease - she invented spaces to counter these experiences, providing protection with thresholds to achieve varying degrees of intimacy. Changing proprioceptive sensations resulted in new space designs which allowed for multi-directional experiences -horizontally and vertically. Another student set herself the task of designing a shelter for recreation and relaxation in the English Gardens in Munich. She addressed different modes and qualities of movement that initiated the design of corresponding architectural counterparts of spatial typologies. She then composed such typologies into a perpetual sequence of spaces in a circular building, inviting the ambulating exploration of ever-changing spatial experience composed in a choreographic manner. Furthermore, another student introduced subjective, sensual, and descriptive narration - which was introduced as a way to preserve and mediate

\footnotetext{
2 The format of Free Master's Theses allows students to complete their studies working on an individual task, the assignment of which they invent themselves and which they elaborate upon during a period of six months under the supervision of a professor, in this case Prof. Uta Craff, Head of the Chair for Architectural Design and Conception at the Technical University of Munich.
} 
observations from lived experience - as a method for the design process. She therein discovered a tool for anticipating the intended experience in verbalized narrations of imaginary architecture. Starting from the description of her first encounter with the site and the sensual experience of the place, she then continued to elaborate upon her intentions and ideas for the architectural design in a consecutive continuation of this narration. Lastly, the work of a different student made observations on movement, gesture, and touch as a starting point to investigate different stages of spatial framing for sensual ambiances under the overarching notion of poiesis, in relation to the poetics of architecture and the making.

These approaches encourage us to continue and deepen this direction of working in order to be able to develop a methodology from it, thus contributing to the canon of design methodologies. Accordingly, human centered design accordingly not only requires human needs to be satisfied by the design, but also entails the development of architecture in correspondence to sensual, multisensory, and sensorimotor experiences of and with the body.

The integration of bodily awareness and somatic practices with the teaching of architecture and the discipline's discourse is rather rare. One example of addressing body-knowledge in the conveyance of architectural studies has been explored in the architecture department of the Alanus University of Arts and Social Sciences. Here, firstyear students are introduced to different working methods which encourage implementing bodily ways of knowing into architectural design, starting from perception. With the aim to increase the awareness for the bodily sensory, tacit, and sensual experience, somatic practice is introduced to architecture teaching. Proprioceptive knowledge is emphasized, in order to form a reliable basis upon which the design of the built environment and the architectural encasing of the body can be developed. Relating to an understanding of architecture as »indivisible«, which »includes us as humans«, self- and body-awareness are essential to the training of attuned awareness as a prerequisite for perceiving and conceiving architecture (Beeren 2020: 22-29). Within Alanus' architecture education, body-based and somatic practices, which are thereafter intended to infuse the creative and conceptual process, are integrated as part of the curriculum.

According to the proceedings of the completed three-phase cycle, we propose an enactive approach in which the moving body as sensorium, container of knowledge, and medium of impression and expression is 
attributed a central role in the teaching of architecture, fostering its capacity to initiate the investigation and creation of architectural space. In order to allow architecture students to achieve access to the potential of their moving bodies and to bring attention to their body-knowledge in perception, reflection, and creativity, the implementation of somatic practices and the conscientization of the body - its movements, its sensations, and its knowledge - would be a fertile addition to teaching architecture. The integration of body-based practices into the curriculum of architecture schools could be a way to accentuate its relevance and to provide access to body-knowledge in order to actively integrate it into the repertoire of design methodologies.

\section{Attuning Awareness to Bodily Sensations}

This contribution retraces the journey we took, seeking to let knowledge emerge from experience, bringing the body and the incorporated sensuality of perception to the fore of the investigation. The contribution aims to find ways to make explicit how implicit knowledge is acquainted with the process of encountering and experiencing architecture. Memory and experience don't always come to conscious attention, but often go unnoticed. The investigation and active realization of experience gained in a pre-reflected, sensual manner brings the plurality and complexity of perceptual sensations to awareness and increases their accessibility - both with regard to their attentive assembly and their influential integration into the creative process.

Anchored in our memory and incorporated into our repository of experience, the sensations gathered while exploring architectural spaces stay with us as sensual and bodily felt experiences. They predict our knowledge, association, and imagination on spatial situations and constitute the individual's body-based knowledge on architecture and space incorporated into our bodies. As experience is situational, subjective, and very personal, the assemblage of memories - and respectively the basis upon which imagination, creativity, and inventory draw on - is individual to each person. Furthermore, perception does not only depend on prior experience but constitutes a complex, creative, and associative act that brings all counterparts of the lived situation together in a seemingly complete and harmonious entirety.

As Juhani Pallasmaa points out, »experiencing, memorizing, and imagining spatial settings, situations, and events, engage our imaginative skills« 
(Pallasmaa 2014: 34). Furthermore, he continues that »even the acts of experiencing and memorizing are embodied acts, in which lived embodied imagery evokes an imaginative reality that feels similar to actual experience« (ibid.). Herein lies the tremendous potential of introducing body-knowledge and corporeal forms of expression into the discourse and the design process of architecture: As architectural design relies heavily on anticipating future (sensual) experience in the creative process, it can benefit from an increase in awareness of its corporeal, sensual, and somatic efficacy. Increasing awareness of the embodied, inner world of prior experience enables us to broaden the spectrum of design methodologies in architecture; bodily ways of knowing enable a more sensual envisioning of the process of conception and the anticipation of future corporeal, sensual experience in the design process.

\section{Taking the Moving Body into Account}

The awareness of the body in motion forms the anchoring point from which the exploring body reaches out to the surrounding (architectural) world context. By opening a new spatial and imaginary dimension, the exploration with the body allows relation to the space, reaching out into the space, and incorporating the perceived. The sensations collected upon its discovery evoke an internalized world of experience. The stimuli of the external environment initiate inner spaces of experience, the impression of which are then expressed in movement and gestures. In the complexity of this synthetic experience of the interplay of different stimuli, some moments of the experience stand out more clearly than others as moments for particular attention.

Including the body and its sensuality in architecture is to understand experience as a reserve of knowledge for one's own design practice. As José Mateus states in the opening to Mariabruna Fabrizi's and Fosco Lucarelli's publication Inner Space:

»Creativity in architecture is the capacity to consider the given constraints in order to bring together information from different universes and then generate concrete and potentially innovative solutions that may hitherto not have existed« (Mateus 2019: 2).

Accordingly, creative, associative, and anticipatory acts of architectural design and conception are based on this very foundation of assembled 
experience, because as Mateus continues, "creative imagination draws on experience, memory and all the information and know-how accumulated over time« (ibid.). Furthermore, he emphasizes that creative imagination "lives off - and is totally subject to - the quality of perception with which the creator studies, learns about and relates to the world « (ibid.). Therefore, one could argue that the more aware we are of our sensations and experience, the more refined the collection of experiential knowledge is to fuel the creative process and constitute a stable and reliable base of creative imagination and conceptual invention.

In intuitive, subconscious dimensions of decision-making, the knowledge from the body is already taken into account and relied upon. But as an implicit, tacit form of knowledge, it merely goes unnoticed. Hitherto, it is the claim of this text that the more we become aware of how we perceive - meaning how we experience and remember, associate, and imagine - the more we will be willing to actively include our perceptual sensation and experiences in the creative process of conception.

The creative process of searching, creating, and innovating demands a particular specific physical and psychological disposition, an »openness to experience« (Kaufman et al., in: Abraham 2018: 4), a state of internal resonance in which the idea remains a sensation at first, an impulse before a movement. Through movement, the body tends to encompass the essence and develop the idea by making it perceptible and letting it emerge on the surface. Through the corporeal nature of the human body, it relates to the presence of the things that surround it, generating attentive awareness of their physical presence through corporeal resonance. Accordingly, every sensual perception is based on engagement and openness to the experience of presence: »Perceiving is a way of acting (Noë 2004: 1). As Alva Noë points out, however, perception is by no means to be understood as a mere display of the world; the world and its perception is only revealed to the percipients, as soon as they discover its experience. In this sense, perception is neither something that occurs to us, nor something that happens within us, but something one does and is actively involved in (Noë 2004; 2012).

When the body is brought into the design process of architecture, the experiencer is again attributed an enactive role, as the way in which prior experience is gained determines the wealth of memory we rely upon as the basis of the creative process. Physical movement and corporeal exploration constitute sensations, which result in incorporated experiences 
and memories. Contained within the body, they are retraceable upon their recalling and reconsideration. Embedded in the cultural context of collective memories and narratives, as well as the individual, subjective impressions and sensations gained in experience, as well as manifold dimensions of knowledge are layered to form the basis that we access in mental processes of remembrance, association, and creative thought. Mental processes themselves are inner movements relating to the mind and body. Retracing mental processes with the body allows us to not only reconnect to memories, but to actually relive them. When attention is focused on these inner movements, the spontaneous expression of very vivid impressions is able to emerge. They demand a certain vigilance, implying high receptivity, both internally and externally in order to capture the whole expression. A combination of focus, awareness, and letting go allows the creative process to reach a deeper level.

Before being formulated, these moments emerge in our senses within the dialogue between the body and mind. They initiate the elaboration of creative processes and the inception of artistic statements. Taking into account the ability to consciously live these moments of particular attention enables access to a further creative process, a creative practice that invites the architect to open new perspectives and sensual spaces for creation. In architecture, different divisions of mental processes - intellectual and creative thought - are at play, which contribute to varying attempts to the creative process (cf. Abraham 2018: 4).

Emphasizing the manifoldness of experience and its ability to bring forth imagination and creativity results in the revelation of particularly sensual ways of anticipation.

\section{Bringing Tacit Knowledge to Consciousness}

Architectural design is embedded within a context - topographically, culturally, and in regard to the genius loci of the place - and therefore requires an initial phase of discovery and familiarization with the given circumstances. Perceiving what is there, wondering what to relate to, exploring and investigating the place are perceptual and experiential processes that precede the design. Prior to the process of architectural design, a distinct process of contextual, spatial, and cultural observation creates a basis of knowledge, to which the designing architect returns over and over again in order to testify and verify the decisions, choices, and proceedings in the ensuing process of architectural design and conception: 
»The most significant time is the one preceding the design [...] It is the time when you approach a context, most of the time as a stranger, and you start a journey literally, walking along the landscapes, streets and houses, or through the words and images of books, the sounds of songs or unknown languages, the refrains of popular tales and traditions. This stime of the traveller collects hints of the culture of a place and traces an open map where many other different information lay and rest-such as the brief of an assignment, the budget, local building regulations and construction technique and materials available - somehow alike the pebbles and shells brought to the shore from the sea that appear and disappear at every new wave« (Torzo 2019: 109-110).

Just as the "pebbles and shells" that emerge and vanish, reappear and dissolve with the ocean's tide or the sprawl of sand, memories and sensations from experience and observation often go unnoticed, or only briefly emerge before they are blurred again with ever-changing, indulging recall and the loss of memories. While exploring the terrain of the architectural task, - both physically and in a figurative sense - various dimensions of »experience and know-how, accumulated over time« (Mateus 2019:2) are taken into account. In order to be able to achieve these more decisively, we need to ask: where are these memories contained and how can they best be accessed?

Here, we argue that they are incorporated into the body, inscribed into the sensual and corporeal experience, embodied in the body-knowledge. And although such memories might lie unnoticed beyond the surface of conscious comprehensibility, they can be brought to attention - in particular through bodily means. As we retrieve bodily sensation with the body, we omit their translation into conscious thought and verbalized expression. Rather, the tacit knowledge from sensual, bodily experience emerges through the body in pre-reflected ways of expression, through movement and gesture, in corporeal and somatic articulations.

\section{Dedicating Vigilance to Movement, Gesture, and Touch}

Movement is an inevitable prerequisite for the experience of space. Only through shifting perspectives can a space be perceived as such. The complexity of a building only reveals itself upon its exploration (MerleauPonty 2003[1945]). The figure of movement, initiated by the layout and sequence of spaces, and spatial experience reciprocally condition one 
another (Janson/Tigges 2014: 118-120). Gesture is an articulate movement of expression, indicating a specific quality, character, or even significance. Bodily gesture finds an equivalent in architectural and spatial gesture (Janson/Tigges 2014: 144-146). Furthermore, the appropriation and use of architectural structures require gestural movements to react and refer to them: The hesitant step on a threshold, the turning of the wrist to open a door handle, the welcoming gesture of opening a door, or the caressing of a hand rail. Gestures conducted in relation to architecture, often go unnoticed in the recalling or envisioning of impressions of architectural experience.

Beyond the movement and gesture conducted in space and time, touch indulges beyond the sensory response to the architecture and addresses the sensual, tangible dimensions of physical encounter. Materiality and texture, tactility and haptic come into play and amplify the sensorial engagement even further. Not only does touch involve immediate contact with the physicality of a building, but it also refers to the sensation of being touched and moved by this encounter.

All dimensions of movement, gesture, and touch are inherent parts of the experience of architecture and are thus anticipated in the design. In a lecture on her design for the Belgian design brand Maniera, architect Francesca Torzo explored how gesture and movement form the initiation into the design process - both for architectural space and for objects of quotidian use - and how in response to the respective space or object, we relate to the world:

»The way in that we move, touch, use, or better said, live objects and spaces, speaks about who we are - and who we are is a layered certification of time« (Torzo 2020).

Observations on quotidian gestures formed the basis from which Francesca Torzo examined movement patterns that her furniture and quotidian objects respond to. To her, these quotidian objects are embedded in the context of what she calls the domestic landscape, defined as: "the domestic landscape is a scene where we find intimacy. It is also a setting, a place. A place where we can relieve our mind, and travel with the mind« (ibid.). From her studies of movement, gesture, and touch within this setting, she explores how to complement this landscape with elements that respond to the elaborate characteristics of movement, either providing them with an initiation, continuity, or counterpart, each embodying the awareness of the intimacy and sensuality of the realm of quotidian domestic life. Objects, furniture, 
and clothes - just like architectural spaces - are designed to incorporate the movements attributed to their playful exploration, use, and appropriation. They respond to them, guide them, or create the freedom to discover them.

Francesca Torzo explores the gestures and movements evoked in correspondence with places, spaces, and objects. Investigating the notion of corporeal needs, she creates objects made for enactive encounters and invites one to engage with them physically, sensually, and through movement. She emphasizes the need to study how people move in particular situations and in relation to specific objects in order to be able to design along with the requirements of these movements as well as to create components that interact with and reciprocally respond to them. Movement and sensual engagement are not only stimulated in sensual and perceptual experiences of objects, furniture, and architectural spaces, but are anticipated in the design process and therefore become inherent to it.

The architect Nicolai Bo Andersen explores the relevance of physical architectural models as a tool and technique to implement sensual and sensory experience in the design process. He emphasizes their capacity to invite physical encounter and bodily engagement, including the full sensory spectrum, because, as he states »the architectural model is - in contrast to the computer rendered image - a physical, three-dimensional thing that I can touch, walk around, and maybe lift and hold in my hand«. This is of particular value, because, as he continues, "perceiving an architectural model involves all the senses of the human body as well as the motor system, not only sight (Andersen 2021: 26). Accordingly, he argues that by involving all the senses and their complex synesthetic interplay, the encounter with the physical architectural model $»$ is richer and more nuanced than the perception of the two-dimensional image (ibid.). Under the superordinate question of how exactly it is different to the perception of the plain image and how we, as perceivers, relate to it and experience it differently, Anderson introduces a variety of modes to look at the image, aligned with Husserl's phenomenological observations on »physical image«, »mental image«, »image object«, and »image subject« (ibid.: 28). Beyond two-dimensional representations - however physical their presence or how sensual their perception may be Andersen emphasizes the qualities of the models as relating to all senses and allowing for movement, touch, and an actual opportunity to relate to it spatially and through movement. Other than the gaze at an image or the perception of an object, the physical model allows for corporeal, sensorimotor involvement: 
»I don't just look at the architectural model with my eyes. I perceive the three-dimensional totality involving my whole body. In the model of the city, I perceive each building volume as individual bodies, like playful figures I can grab and hold in my hand. [...] What I perceive is not simply the formal pictorial qualities of a flat image, but rather physical properties closer to a real work of architecture, for example weight, solidity, consistency, thermal conductivity, textural effects, gravitational impact and changing light conditions« (Andersen 2020: 30).

The great benefit of architectural models rests in their interactivity: As they cultivate engagement through movement, gesture, and touch, they intrigue sensual and bodily investigation. According to their particular degree of abstraction - through different scales, miniatures, and replication in different material - they allow for association and invite the observer to embark on an associative and creative sensual encounter through movement. In this way, the architectural model enables an all-encompassing, holistic approach to experience which engages the entire body and all of its senses. It is a tool and medium in the anticipatory and creational processes of architectural design and it prompts the experiencer to engage with it physically, sensually, and through movement.

\section{Architecture Imagery}

In the sense of inter-subjective conviviality and exchange, the subjective experience - although highly individual, situational, and temporary - thus relates to others. The subjective approach makes it possible to develop knowledge starting from oneself, to include the sensuality of one's own body and to draw conclusions from this for the creative and research process - especially in the context of architectural design. It is the familiarity with previously unprecedented spaces that reveals that an experience of the not-yet-present is possible in its imagination. Although imagination or visualization is literally linked to the visual, the impression of having already passed through the architectural edifice in the imagination reveals that not only is the dominant visual perception anticipated in architectural design, but that multisensory, sensual experience as a holistic process of encountering space is as well.

This inventive imagination of future realities is linked to highly complex processes that call into question the chronology of temporal sequences. 
Memory and present experience are integrated into the conception and design process of what is yet to come, as well as initiating it. In this sense, they thus stand for themselves and yet reach beyond themselves in equal measure.

In architectural design, pre-reflexive intuitive knowledge and analytical, reflective concern converge. In this process, however, it is far easier to deal with rational parts than vague, working ones from one's own sensibilities. Nevertheless, the latter are a necessary and integral part of the design process, because "if I allow the factual course of the design process to be repeatedly confused by subjective and unreflected ideas, I acknowledge the importance of personal feelings in designing (Zumthor 2010: 21, author's translation). An increased engagement with pre-reflective perceptions facilitates recourse to the same memory and thus makes it possible to integrate them more intensively into the design process:

»The process of designing is based on a constant interplay between feeling and reason. The feelings, the preferences, longings, and desires that arise and want to take shape are to be examined with a critical mind. Feelings tell us whether abstract considerations are coherent.«(Ibid.)

This interdependent nature of rational and pre-reflective knowledge requires an equal approach to both, with abstract, analytical, and considered knowledge being more easily learned, communicable, and more established as a form of knowledge. Accordingly, we argue that the body - and bodyrelating, corporeal, and somatic practices in particular - possess the opportunity to make immanent tacit and pre-reflective knowledge explicit and accessible. The aim is to negotiate the predominance of vision in imagination processes and to include an enlarged polyphony of senses to do justice to the complexity of multisensory sensual experience. In order to do so, in conjunction with the notion of »Dance Imagery« in contemporary dance - and dance in general - we introduce the concept of a sensual »Architecture Imagery«.

In contemporary dance, kinesthetic forms of creativity (Abraham 2018) that have been introduced to the architectural experience in exercises from which the presented proceedings of the latest phase of the cycle were derived are explored. Bodily-kinesthetic intelligence, as psychologist Howard Gardner frames body-knowledge, is thereby fused with architecture and made explicit through bodily means (Gardner 1983). Therefore, 
recent findings from neuroscience on embodied cognition are introduced to applied forms of working.

As a »mental practice of movement« »Dance Imagery« forms a working method to anticipate and observe dance in imagination. Through the visualization of dance movements, the actual movement and its multi-sensory experience are mentally recreated. All senses are engaged to invent or recreate the actual dance experience mentally. Imagined movements result in inner movements, which allow for the study of actual physical movement as a sole mental-sensual procedure (cf. Liu et al. 2004). The reconsideration of former movements in the mind enables us to recreate information stored in our memory and create and invent new information through imagination. The perception finds an immediate continuation in associations and further implementations.

Learning from the actual physical exploration and taking into account the manifold sensual and perceptual dimensions involved in it, it becomes possible to relate to it again only through mental processes. Working with "Dance Imagery« includes the principles of visualization: envisioning oneself while dancing and tracing the sensations and feelings evoked by this dance. As a technique applied in training, teaching, and production work, »Dance Imagery " grants access to the inner world of experience, memory, and the senses.

Creative and inventory processes in architecture are usually visualized using architectural means and various mediums of representation, such as sketches, plans, models, mock-ups, and images. Visualization here usually entails the act of finding ways to convey ideas to others and making them visible. The subjective process of envisioning is rather secondary. Learning from the working methodologies attributed to "Dance Imagery«, this concept could be translated into a visualization technique that incorporates polysensory imagery, using the physicality of all the senses to enable one to feel the imagery. Accordingly, a few guiding questions would arise: How do you envision yourself in the architectural space? Do you feel the sensual effects of it and how does your body relate to them?

It is the a great achievement for lively imagery when »vivid images are realistic, detailed, and clear and include all of the requisite, senses, thoughts, and emotions " (Taylor/Taylor 1995: 88). In regard to their constitution, Jim and Cice Taylor explain that "vivid images replicate actual experience, increasing the likelihood of proper performance in the future (ibid.). Beyond the recalling and replication of actual experience, the notion of 
vivid images as sensual »Architecture Imagery« can therefore provide the opportunity to »live« an envisioned scenario during the anticipating course of architectural design. If the sensations of envisioned experience are precisely observed, they can provide direct information. From feelings like calm or ease, serenity or vastness, confinement or oppression, associations between relating spaces can occur immediately. Spatial typologies, characteristics, and the ambiance of a place are evoked by these space-relating sensations and allow for the emergence of envisioned architectural designs as complements and counterparts to the »Architecture Imagery«.

Movement- and motion-relating practices of any kind provide increased awareness of the sensual and corporeal polysensory experience in architecture and increase the designing architects' capacity to anticipate future experiences of architectural spaces throughout the design process. In addition, the practice of contemporary dance provides greater access to movement, with particular focus on the plurality of characters, qualities, and patterns of movement that have an attentive awareness to the perceptual and expressive modes of the body. Beyond the field of contemporary dance, here, the moving and sensing body is an integral part of a cultural and artistic practice: Dance has a different relationship to the body insofar as it reflects the poiesis and poetics of movement. In this sense, movement is not purposeful and utilitarian, but rather of an aesthetic nature, e.g. emotional, abstract, formalistic, imaginary, sensual, creative, and conceptual. The dancer is an actor in an artistic event and in this sense, introducing somatic practices and ways of working from contemporary dance to the discipline of architecture means translating aesthetic, creational, and investigative procedures from one creative and artistic process to another. 
References

Abraham, Anna (2018): The Neuroscience of Creativity, Cambridge University Press, doi: 10.1017/9781316816981

Andersen, Nicolai Bo (2021): »Architecture Enactment. Understanding the Architectural Model as Embodied Participation «, in: Alberto Calderoni/Carlo Gandolfi/Jacopo Leveratto/Antonio Nitti (eds.), STOÀ 01 l.1/2, Naples: Thymos Books, 26-43.

Beeren, Willem-Jan: » sthat Architecture is Something Indivisibler. The Perception of People and Architecture «, in: Perceiving Architecture, Mensch + Architektur 02/2020, 22-29.

Gardner, Howard (1983): Frames of Mind. The Theory of Multiple Intelligences, New York: Basic Books, https://www.academia. edu/36707975/Frames_of_mind_the_ theory_of_multiple_inteligences, accessed July 20, 2021.

Havik, Klaske (2006): »Lived Experience, Places Read: Toward an Urban Literacy«, in: Grafe, Christoph/Maaskant, Madeleine/ Havik, Klaske (eds.): OASE 70, 10/2006, 37-44.

Jäkel, Angelika (2013): Cestik des Raumes. Zur leiblichen Kommunikation zwischen Benutzer und Raum in der Architektur (Cestures of Space. On the Bodily Communication Between User and Space in Architecture), Berlin: Wasmuth \& Zohlen.

Janson, Alban/Tigges, Florian [2013]: Grundbegriffe der Architektur. Über das Vokabular räumlicher Situationen. - English translation by lan Pepper: Fundamental Concepts of Architecture. The Vocabulary of Spatial Situations, Basel: Birkhäuser, 2014.

Kaufman, Scott Barry (2016): Openness to Experience and Creative Archivement in the Arts and the Sciences, https:// scottbarrykaufman.com///wp-content/ uploads/2013/11/Kaufman-2013.pdf, accessed July 20, 2021.
Liu, Karen P./Chan, Chetwyn C./Lee, Tatia M./Hui-Chan, Christina W. (2004): »Mental imagery for promoting relearning for people after stroke: a randomized controlled trial«, in: Archives of Physical Medicine and Rehabilitation 85, 1403-1408, doi: 10.1016/j.apmr.2003.12.035

Louppe, Laurence [1997]: Poétique de la danse contemporaine, Brussels: Contredanse. - English translation by Sally Gardner: Poetics of Contemporary Dance, Alton, Dance Books, 2010.

Mateus, José (2019): »Imagination«, in Mariabruna Fabrizi, Fosco Lucarelli: Inner Space. Triennal de Arquitectura de Lisboa, Barcelona: Polígrafe.

Merleau-Ponty, Maurice [1945]: Phénoménologie de la perception. - English translation: Phenomenology of Perception, transl. by Colin Smith (2003[1962]), London/New York: Routledge \& Kegan Paul.

Noë, Alva: (2004): Perception in Action, Cambridge, MA: The MIT Press.

Noë, Alva: (2012): Varieties of Presence, Cambridge, MA: The MIT Press.

Pallasmaa, Juhani (2014): »Space, Place, and Atmospheres«, in: Christian Borch (ed.): Architectural Atmospheres. On the Experience and Politics of Architecture, Basel: Birkhäuser.

Schmitz, Herrmann (1999): System der Philosophie, Bd. III: Der Raum, 5. Teil: Die Wahrnehmung (System of Philosophy, Vol. III: Space, Part 5: Perception), Bonn.

Schmitz, Herrmann(2005): Situationen und Konstellationen: Wider die Ideologie totaler Vernetzung (Situations and constellations: Against the Ideology of Complete Interconnectedness), Freiburg: Herder.

Taylor, Jim/Taylor, Ceci (1995): Psychology of Dance, Champaign, IL: Human Kinetics Publishers. 
Torzo, Francesca (2019): »Relation and Memory«, in: Uta Graff/Katleen Nagel/ Felix Zeitler, Schwarze Räume/Black Spaces, 99-113.

Torzo, Francesca (2020): »Gestures. These Are Only Hints and Guesses. A Project for Maniera «, Lecture, August 12, 2021, The Architecture Foundation, 100 Days Studio, https://www.youtube.com/ watch?v=AiePloB25BM, accessed July 20 , 2021.

Zumthor, Peter (2006): Atmosphären (Atmospheres), in: Archplus 178, 06/2006, 30-37.

Zumthor, Peter (2010[2006]): Atmosphären (Atmospheres). Basel: Birkhäuser. 


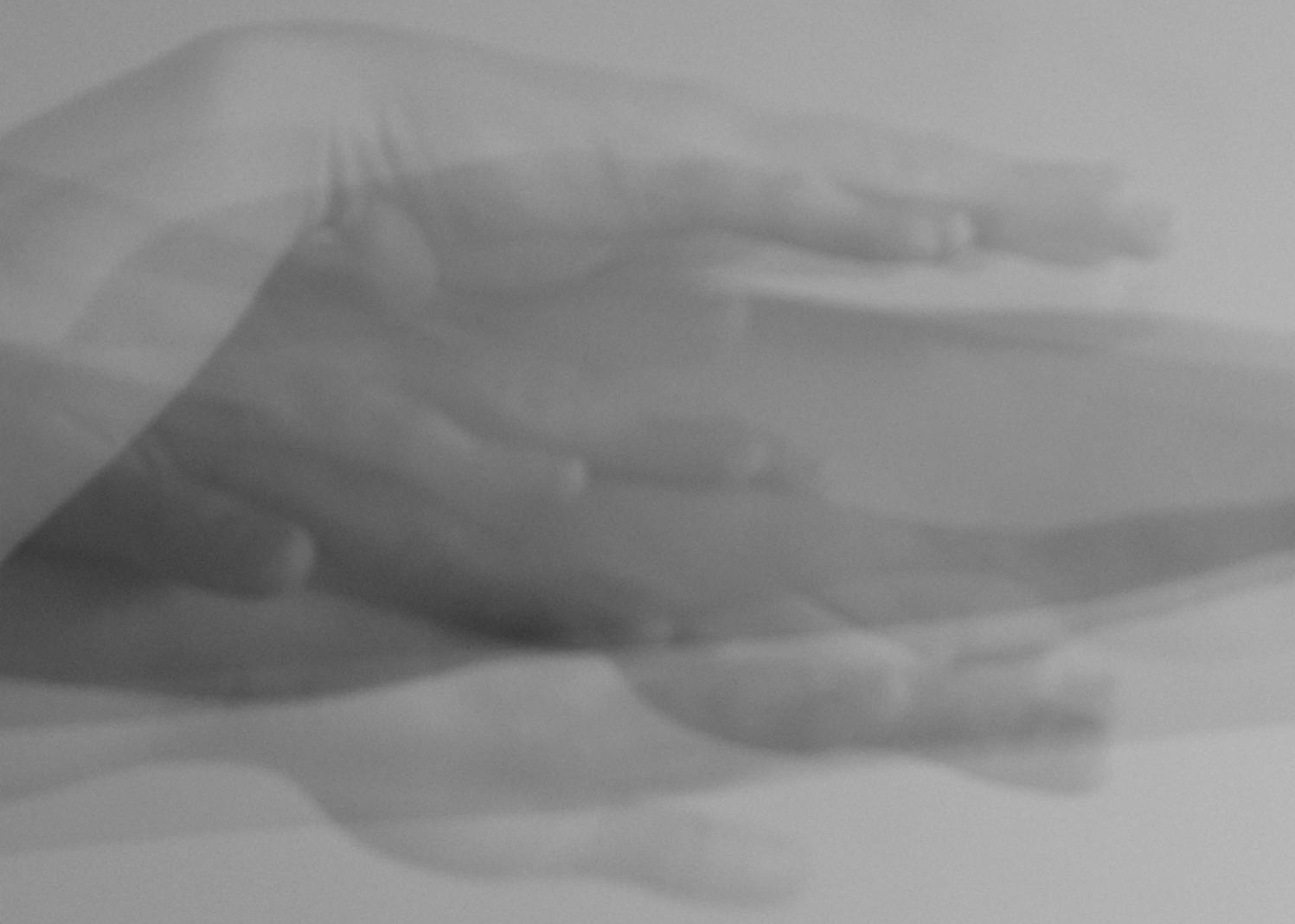


Friederike Drewes: "running “ seminar work, 2019. 
